\title{
Effect of Carbon Nanofibers (CNF) on The Crystallization Kinetics of Polyphenylene Sulfide (PPS)
}

\author{
Bladimir A. Ramón-Valencia ${ }^{1}{ }^{*}$, Gonzalo Moreno Contreras ${ }^{2}$ and Jacipt A. Ramón-Valencia ${ }^{3}$ \\ ${ }^{1}$ Faculty of Engineering and Architecture, GIMUP group, University of Pamplona, Colombia. \\ ${ }^{2}$ Faculty of Engineering and Architecture, GIMUP group, University of Pamplona, Colombia. \\ ${ }^{3}$ Faculty of Engineering and Architecture, GIAAS group, University of Pamplona, Colombia. \\ *Corresponding Author (gmoren@ hotmail.com)
}

Received Date : January 02, 2022 Accepted Date : January 29, 2022 Published Date : February 07, 2022

\begin{abstract}
The presence of a reinforcement in polymeric materials can cause alterations in their physical properties, and increase the crystallization rate of their polymeric matrix. Therefore, this research work was oriented toward the incorporation of different percentages of carbon nanofibers (0.6-1-3 and 5\%) in a PPS thermoplastic matrix, with the purpose to establish and understand each one of the variables that control crystallization kinetics. The results showed a gradual decrease in crystallization times for contents of up to $5 \%$ of $\mathrm{CNF}$, where carbon nanofibers act as nucleation sites, accelerating the crystallization process. According to the values obtained in the Avrami exponent, these fell within a range that oscillates from 2.5 to 3 for pure PPS and PPS $/ 1 \% \mathrm{CNF}$ which indicates that the presence of carbon nanofibers does not have an effect on the nucleation mechanism of polyphenylene sulphide crystalline phase, thus suggesting crystallization with heterogeneous nucleation and two-dimensional growth with circular geometry.
\end{abstract}

Key words: Crystallization kinetics, carbon nanofibers, Avrami theory, polyphenylene sulfide.

\section{INTRODUCTION}

Polyphenylene sulfide (PPS) is an engineering semi-crystalline thermoplastic, which possesses a combination of properties such as chemical resistance, fire resistance, and easy processing which is why it is widely used in auto parts, manufacturing industries, aerospace, and chemistry. However, due to its brittle behavior the impact resistance is considered relatively low and consequently the applications for pure PPS are limited. To improve the mechanical properties of the resin, carbon fiber is widely used to reinforce pure PPS due to its high thermal stability, excellent strength and rigidity [1-3].
The properties of thermoplastic polymers largely depend on the degree of crystallinity and the morphology of the molecular structure, which in turn, are influenced by the conditions of the manufacturing process in which changes in the material's crystallinity are generated, and consequently, there are alterations in the mechanical properties of polymeric materials [4-6].

The presence of a reinforcement in polymeric materials can cause alterations in its physical properties, since this was discovered; several papers related to the influence of a second organic or inorganic component on the crystallization kinetics of phenylene polysulfide have been reported in literature [7]. Jog and Nadkarni [8], analyzed the behavior of pure PPS and composites reinforced with $40 \%$ glass fibers using the Avrami equation, estimating an average value for the Avrami exponent $n=2.55$ for the resin reinforced with glass fibers and $n=2.23$ for pure PPS. These values suggested a heterogeneous nucleation mechanism with diffusion-controlled growth, similarly, the nucleating effect exerted by glass fibers on pure PPS was verified. On the other hand, studies on the evolution of crystallinity on PPS composites reinforced with carbon fibers determined an increase in the mean crystallization time [9]. PPS/PES polyethersulfone mixtures were analyzed in a temperature range between $240-260{ }^{\circ} \mathrm{C}$ in which the crystallization rate increased to values of $10 \%$ in PES [10].

With the discovery of materials at the nanoscale, a new possibility opens up for the production and characterization of a new generation of composites that allow us to keep the same properties traditional materials have [11,12]. Currently, carbon nanofibers (CNF) are within this group, where great scientific interest has been shown in them as a promising reinforcing material for polymeric matrices because of their high ratio (diameter/length) [13]. In recent years, a great effort has been made to study the kinetic behavior of thermoplastic materials reinforced with nanometric particles. The results presented by K. Lozano, EV Barrera [14], in their research work, they analyzed the effect that CNFs have on the crystalline structure of polypropylene, for which an increase 
in both the degree of crystallinity and the crystallization rate due to increased nucleation sites was observed.

According to the approaches mentioned above by the different authors on the crystallization rate of thermoplastic materials and due to the little knowledge related to the kinetic behavior of a second phase at the nanometric scale, the research paper below, oriented towards the incorporation of different percentages of CNFs carbon nanofibers within a PPS thermoplastic matrix, is essential in order to establish and understand each of the variables that control crystallization kinetics.

\section{METODOLOGY}

\subsection{Materials}

The carbon nanofibers used were supplied by Grupo Antolin S.A, these are obtained from the thermal decomposition of hydrocarbons such as benzene and methane in the presence of metal particles that act as catalysts through a fluidized bed [15-16]. The typical structure of this materials class is bamboo-like, with diameters ranging between 30-300 nm and lengths over $80 \mathrm{~m}$.

Polyphenyl-sulfone (PPS) was supplied by Frontron TICONA ENGINEERING POLYMERS, reference 0320, it is a crystalline polymer and is produced from the polymerization of 1,4-dichlorobenzene with sodium sulfide, using $\mathrm{N}$-methylpyrridone as solvent.

\subsection{Nanocomposite preparation}

All the mixtures were prepared in a BRABENDER model 350 E mixer with capacity of 50 grs, the proportions of CNFs were 0.6-1-3 and 5\%. Initially the samples were kept in an oven at $70^{\circ} \mathrm{C}$ for 24 hours in order to eliminate possible humidity, later the combination of materials was carried out by means of a melt mixing process at a temperature of $300^{\circ} \mathrm{C}$ for $10 \mathrm{~min}$ while avoiding degradation of the materials.

For the manufacture of the samples, a press (Collin) was used. The material obtained from the mixer was pressed using a hydraulic mechanism, where it was subjected to an initial pressure of 4 bars and a temperature of $300^{\circ} \mathrm{C}$ for 5 minutes in order to soften and distribute it in the mold, subsequently, it was subjected to a final pressure of 240 bars for a time of 2 minutes, compacting the material to its final shape, it was then removed from the press and rapidly cooled in water in order to keep it from crystallizing.

\subsection{Differential Scanning Calorimetry (DSC)}

Crystallization were carried out in a DSC 2920 from TA instruments under argon atmosphere conditions, the weight of each of the samples ranged approximately between 5 and
$10 \mathrm{mg}$. Fusion temperature $\left(T_{m}\right)$ and enthalpies of fusion $\left(\Delta H_{\mathrm{m}}\right)$ were measured from endothermic peaks, the same way the crystallization temperature $\left(T_{m}\right)$ and enthalpies of crystallization $\left(\left(\Delta H_{\varepsilon}\right)\right.$ were measured from exothermic peaks. The degree of crystallinity for each of the compositions was determined through the following equation:

$$
X_{C}=\frac{\Delta N_{f}}{\Delta N_{f} W_{m}} \times 100
$$

Being $X_{e}(\%)$ the crystalline fraction in percent calculated from the enthalpy of fusion $\left(\Delta H_{f}\right)$ on the standard crystallization enthalpy for crystalline PPS100\% $\left(\Delta H_{f}{ }^{\mathbb{C}}\right)$. The theoretical value of $\Delta H_{f}$ is of $76.5 \mathrm{~J} / g$ [10], and $W_{\mathrm{m}}$ corresponds to the polymeric matrix's weight fraction in the composite material.

For the study of isothermal crystallization kinetics, pure PPS and PPS $/ 1 \% \mathrm{CNF}$ were taken as reference. The thermal cycle applied under isothermal conditions, as observed in Fig. 1, consisted of heating up to $330^{\circ} \mathrm{C}$ at a rate of $20^{\circ} \mathrm{C} / \mathrm{min}$ in 5 minutes in order to eliminate the thermal history of the material, later they were cooled until reaching crystallization temperatures $T_{c}=248{ }^{\circ} \mathrm{C}, 250^{\circ} \mathrm{C}, 252^{\circ} \mathrm{C}$ to determine the evolution of crystallinity as a function of time until the crystallization was considered complete.

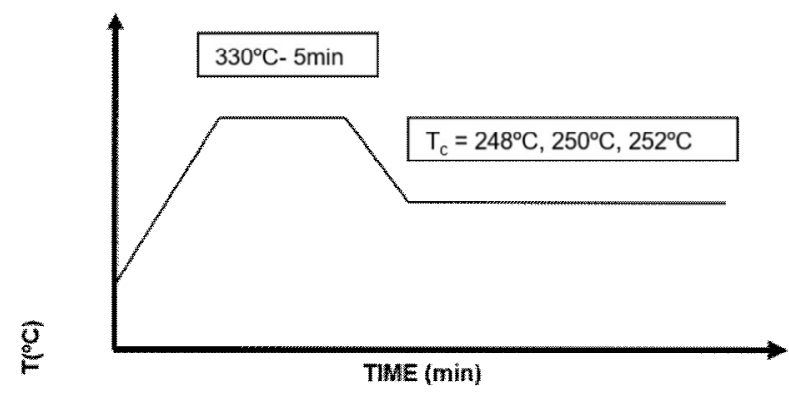

Figure 1: Scheme of the thermal treatments for the kinetic study using DSC.

\section{RESULTS AND DISCUSSION}

\subsection{DSC analysis of composites}

Taking the baseline of the areas obtained in the thermograms for exothermic peaks obtained in the DSC as a reference, in Fig. 2, the heat flow variation Vs the crystallization time is represented for pure PPS and different contents of carbon nanofibers identified by a series of bands for each of the systems. The semi-curve that corresponds to pure PPS is represented by the wideband, and for the reinforced systems, a decrease in band length is observed as the percentage of nanofibers increases. This decrease in band length is associated to a gradual reduction in crystallization times for contents of up to $5 \% \mathrm{CNF}$, where carbon nanofibers act as nucleation sites accelerating the crystallization process. 


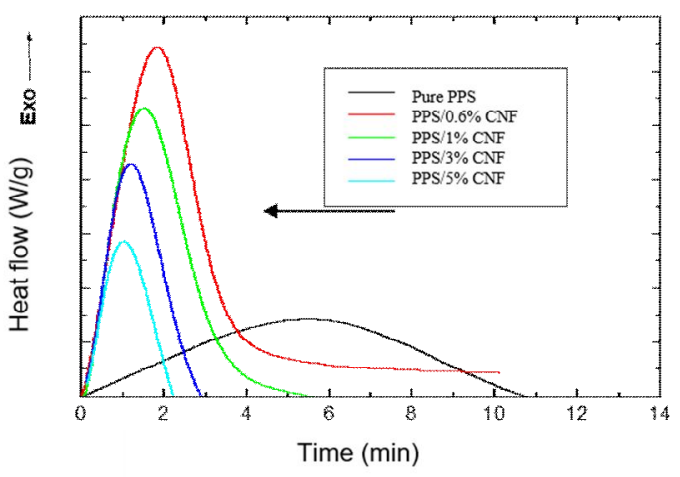

Figure 2: Isothermal crystallization thermograms for PPS/\% $\mathrm{CNF}$ composites at $248^{\circ} \mathrm{C}$.

Temperature scans were performed in the DSC for each of the composites. In Fig. 3, the heat flow is represented against temperature for each of the PPS and nanofiber-reinforced systems. The glass transition temperature according to the curves is seen around $90^{\circ} \mathrm{C}$, similarly, a displacement of this transition is observed as a result of the impediment exerted by the carbon nanofibers, hindering the molecular movement of the chains associated with the amorphous part of the material, this effect looks more representative as we increase the content of nanoparticles. Table 1 shows some of the properties obtained in the DSC thermograms.

Table.1 Properties of DSC scans for PPS/\% CNF.

\begin{tabular}{|c|c|c|c|c|c|}
\hline MATERIAL & Tg & $\Delta \mathbf{H f}$ & $\Delta \mathrm{HRC}$ & $\mathrm{Xc}$ & $\operatorname{XRC}\left(125^{\circ} \mathrm{C}\right)$ \\
\hline & $\left({ }^{\circ} \mathrm{C}\right)$ & $(\mathrm{J} / \mathrm{gr})$ & $(\mathrm{J} / \mathrm{gr})$ & $(\%)$ & $(\%)$ \\
\hline Pure PPS & 90 & 34.59 & 23.51 & $\begin{array}{c}45.2 \\
1\end{array}$ & 30.73 \\
\hline PPS - $0.6 \%$ CNF & 95 & 39.24 & 19.24 & $\begin{array}{c}51.2 \\
9\end{array}$ & 25.15 \\
\hline PPS - $1 \%$ CNF & 96 & 34.12 & 15.84 & $\begin{array}{c}44.6 \\
0\end{array}$ & 20.70 \\
\hline PPS - 3\% CNF & 97 & 32.60 & 12.60 & $\begin{array}{c}42.6 \\
1\end{array}$ & 16.47 \\
\hline PPS - 5\% CNF & $\begin{array}{c}97 . \\
5\end{array}$ & 30.91 & 8.67 & $\begin{array}{c}40.4 \\
0\end{array}$ & 11.33 \\
\hline
\end{tabular}

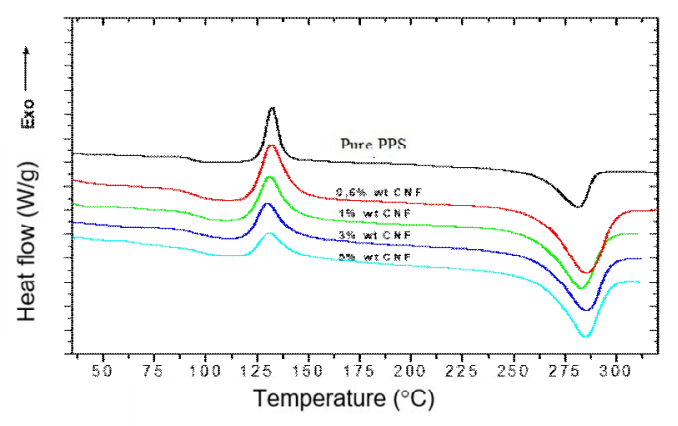

Figure 3: Temperature scans for PPS/\%CNF composites.
On the other hand, it is evident that the crystallization peak at $\mathrm{T}=125^{\circ} \mathrm{C}$ shows a reduction due to the decrease in the crystalline phase of PPS and the increase in the percentage of nano-loads, see Fig.4.

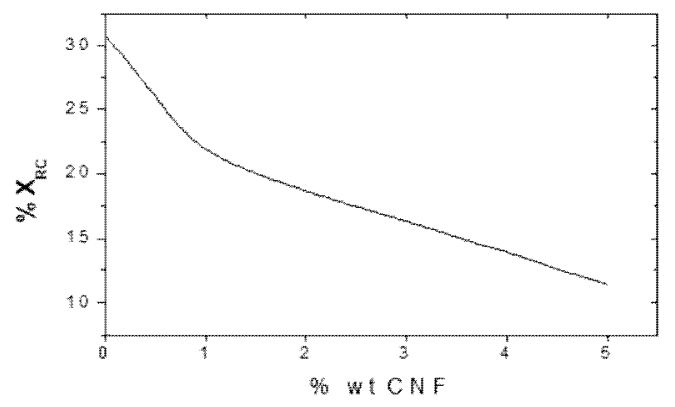

Figure 4: Variation of the recrystallization peak at $\mathrm{t}=125^{\circ} \mathrm{C}$ in function of the \%WT CNF percentages.

Regarding the degree of crystallization, see figure 5, an increase is observed for nanofiber contents of $0.6 \%$, this increase is associated with a good nanofiber dispersion, which favors the PPS's crystal lattice structure due to better alignment during formation. In contrast, for percentages greater than $0.6 \%$ there is a decrease in the crystalline fraction, which is caused by a decrease in the space between the nanofibers, therefore, chain movement is affected by the hindrance that spherulites have for their growth.

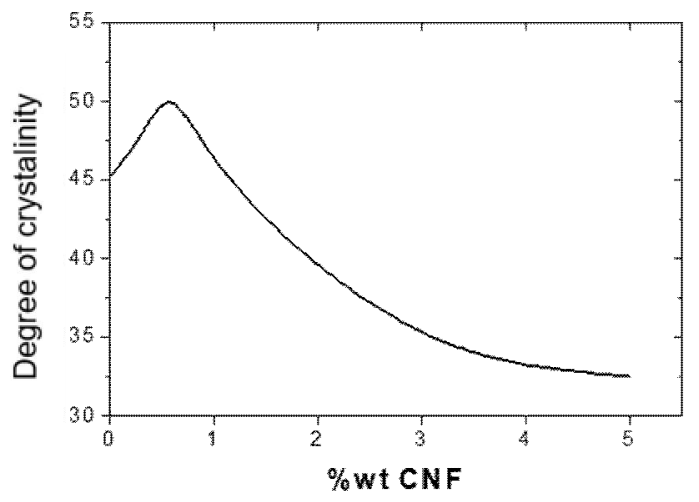

Figure 5: Variation of the degree of crystallinity as a function of the CNF nanofiber percentages.

Among the approaches most used to study the phenomena related to the crystallization kinetics of polymers is Avrami's theory, which relates the increase in the crystalline fraction as a function of time using the following equation $[17,18]$.

$$
X_{t}=1-e^{-k t^{n}}
$$


Bladimir A. Ramón-Valencia et al., International Journal of Emerging Trends in Engineering Research, 10(2), February 2022, 108 - 113

Applying logarithm to each side we get:

$$
\log \left[-\ln \left(1-X_{t}\right)\right]=n \log [t]+\log [K]
$$

Where $\mathrm{n}$ is a constant called Avrami exponent and provides us with information about the type of process that occurred during nucleation and growth, while $\mathrm{K}$ is $\mathrm{a}$ temperature-dependent constant and is related to the speed of radial growth of spherulites, as well as the density of the nuclei formed from the melt.

Another important parameter that directly relates to the Avrami constants described above is the mean crystallization time or $\tau_{1 / 2}$ and is defined as the time required to reach $50 \%$ of the crystalline fraction:

$$
\tau_{1 / 2}=\left(\frac{\min [}{n}\right)^{1 / n}
$$

The $\mathrm{n}, \mathrm{k}$ values are obtained from the graphical representation of: $\log \left[-\ln \left(1-X_{t}\right)\right]$ vs $\log [t]$. The line of the slope and the cut with the $\mathrm{Y}$ axis represent the Avrami exponent (n), and $\mathrm{K}$ respectively for each of the pure PPS and PPS/1\%CNF systems as shown in Fig. 6.
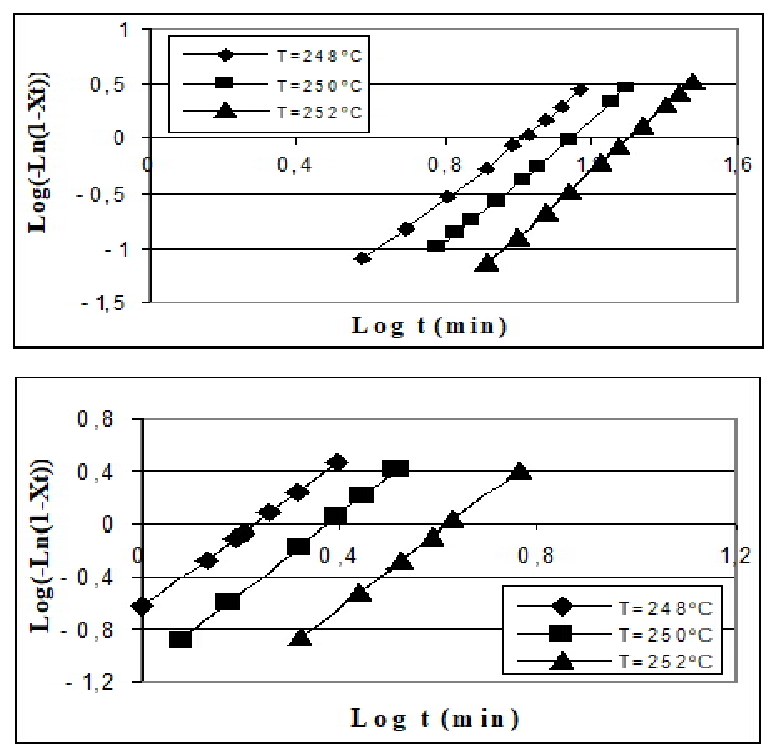

Figure 6: Avrami curves for pure PPS (top) and PPS/1\%CNF (bottom) at different crystallization temperatures (Tc).

The values of $\mathrm{n}, \mathrm{K}$ and $\tau_{1 / 2}$ obtained from the graphs in Fig. 4 , can be summarized in the following table:
Table.2 Values of n, $\mathrm{k}$ and $\tau_{1 / 2}$ of pure PPS and PPS1\%CNF.

\begin{tabular}{|c|c|c|c|c|c|c|}
\hline Tc & \multicolumn{3}{|c|}{ Pure PPS } & \multicolumn{3}{c|}{ PPS1\% CNF } \\
\hline$\left({ }^{\circ} \mathbf{C}\right)$ & $\mathbf{n}$ & $\mathbf{k}(\mathbf{s}-1)$ & $\mathbf{t 1 / 2}$ & $\mathbf{n}$ & $\mathbf{k}(\mathbf{s}-1)$ & $\begin{array}{c}\mathbf{t 1} / \\
\mathbf{2}\end{array}$ \\
\hline 248 & 2.59 & $2.35 \mathrm{E}-03$ & 8.98 & 2.72 & 0.23 & 1.5 \\
\hline 250 & 2.83 & $5.80 \mathrm{E}-04$ & 12.22 & 2.96 & $7.65 \mathrm{E}-02$ & 2.1 \\
\hline 252 & 2.97 & $1.30 \mathrm{E}-04$ & 17.87 & 2.85 & $1.68 \mathrm{E}-02$ & 3.5 \\
\hline
\end{tabular}

According to the values obtained in table 2, the Avrami exponent is between $(2.5$ - 3) for pure PPS and PPS/1\%CNF which indicates that the presence of carbon nanofibers does has no effect on the polyphenylene sulfide crystalline phase nucleation process, meaning that the same crystallization process occurs with heterogeneous nucleation and two-dimensional growth with circular geometry.

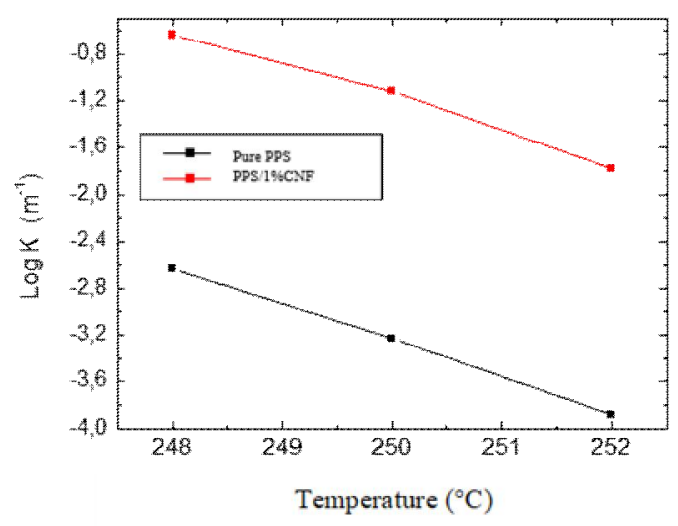

Figure 7: Variation of $\log \mathrm{k}$ at different crystallization temperatures $(\mathrm{Tc})$.

The analysis of crystallization rate was carried out by plotting $\log \mathrm{K}$ against crystallization temperatures (Tc) figure 7 , where the $\mathrm{K}$ value decreases as temperature increases in the pure and CNF reinforced PPS. On the other hand, the incorporation of $\mathrm{CNF}$ increases $\mathrm{K}$ values in relation the pure PPS system, demonstrating the nucleating effect of carbon nanofibers. The results obtained by Ernesto Di Maio based on the crystallization kinetics of PCL/clay nanocomposites showed that the silicate phase acts as an efficient nucleating agent confirmed by the increase in the kinetic constant [19]. Similar results were evidenced in nanocomposites based on a polypropylene matrix reinforced with $1 \%$ carbon nanotubes, confirming that with low load contents, the crystallization process' growth rate increases [20]. 


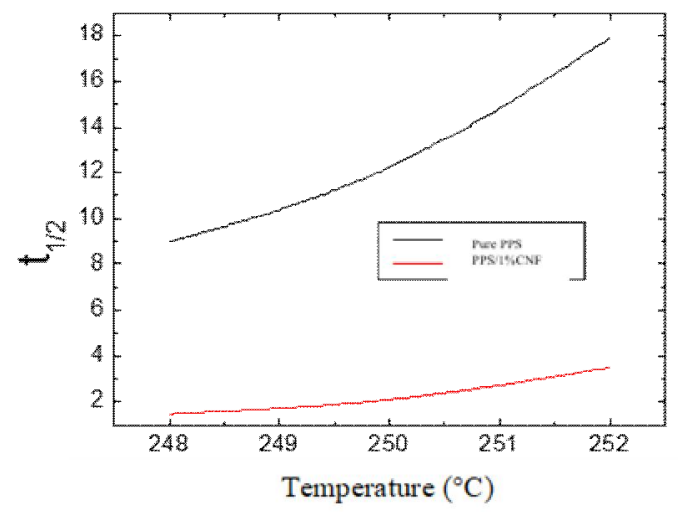

Figure 8: Representation of the mean crystallization time $\tau_{1 / 2}$ in relation to the crystallization temperature.

An important parameter in the crystallization process' characterization is determined by the mean crystallization time measurement $\left(\tau_{1 / 2}\right)$ defined above. In figure 8 it is clearly observed that the average crystallization time is progressively affected by increases in the crystallization temperature, likewise, carbon nanofibers exert an accelerating effect on the crystallization process, reducing the average crystallization times on unloaded PPS. These values are aligned with those obtained by George Z. Papageorgiou [24], where it is appreciated that with the addition of small amounts $\mathrm{Si} 02$ of nanometric size reduces the average crystallization times $\tau_{1 / 2}$ ) in a polypropylene matrix.

Similar effects have been observed for nylon/clay nanocomposites in which for $1.6 \mathrm{wt} \%$ nanoclay contents, the crystallization speed is drastically increased, however, for higher contents there is a decrease in speed [15]. In contrast to the conclusions drawn in the study on carbon fibers reinforced PPS crystallization [9], an inverse effect on the CNF was found, this being related to increased crystallization times as a consequence of the high fraction of carbon fibers, which hinders crystal growth.

\section{CONCLUSION}

The following paper was oriented towards the incorporation of different percentages of carbon nanofibers (0.6-1-3 and $5 \%$ ) within a PPS thermoplastic matrix, with the purpose to establish and understand each of the variables that control crystallization kinetics.

According to the results obtained by differential scanning calorimetry, a decrease in PPS crystallization time is observed as the amount of CNF increases, meaning it is possible that the nanoparticles act as nucleation sites, accelerating the crystallization process.
In relation to the values obtained according to the Avrami exponent, these comprise ranges that oscillate from 2.5 to 3 for pure PPS and PPS $1 \%$ CNF, which indicates that the presence of carbon nanofibers does has no effect on the crystalline phase of polyphenylene sulfide nucleation process, thus suggesting a crystallization process with heterogeneous nucleation and two-dimensional growth with circular geometry.

The average crystallization time is progressively affected with the increase in crystallization temperatures, similarly, carbon nanofibers exert an accelerating effect on the crystallization process, reducing average PPS crystallization times.

\section{REFERENCES}

1. REITZEL, Gunther; REUSCHEL, Gerhard. Polyphenylene sulphide (PPS). Kunststoffe-Plast Europe, 2005, vol. 95, no 10, p. 132-132.

2. HAY, J. N.; LUCK, D. A. The conformation of crystalline poly (phenylene sulphide). Polymer, 2001, vol. 42, no 19, p. 8297-8301.

3. SILVESTRE, C., et al. Crystallization, morphology, and thermal behavior of poly (p $\square$ phenylene sulfide). Journal of Polymer Science Part B: Polymer Physics, 2001, vol. 39, no 4, p. 415-424.

4. NOHARA, Liliana B., et al. Study of crystallization behavior of poly (phenylene sulfide). Polímeros, 2006, vol. 16, no 2, p. 104-110.

5. LEE, T. H.; BOEY, F. Y. C.; KHOR, K. A. On the determination of polymer crystallinity for a thermoplastic PPS composite by thermal analysis. Composites Science and Technology, 1995, vol. 53, no 3, p. 259-274.

6. BOEY, Freddy YC; LEE, T. H. Effect of matrix crystallinity on the buckling failure of a PPS thermoplastic composite. Polymer testing, 1994, vol. 13, no 1, p. 47-53.

7. GUSCHL, Peter C.; KIM, Hyun Seog; OTAIGBE, Joshua U. Effects of a Nd-Fe-B magnetic filler on the crystallization of poly (phenylene sulfide). Journal of applied polymer science, 2002, vol. 83, no 5, p. 1091-1102.

8. JOG, J. P.; NADKARNI, V. M. Crystallization kinetics of polyphenylene sulfide. Journal of applied polymer science, 1985, vol. 30, no 3, p. 997-1009.

9. KENNY, J. M.; MAFFEZZOLI, A. Crystallization kinetics of poly (phenylene sulfide)(PPS) and PPS/carbon fiber composites. Polymer Engineering \& Science, 1991, vol. 31, no 8, p. 607-614.

10. SHAO, Zhecheng. Novel Conducting Aniline-based Materials Using Advanced Palladium Catalysts. 2011. Tesis Doctoral. University of Bristol.

11. ALEXANDRE, Michael; DUBOIS, Philippe. Polymer-layered silicate nanocomposites: preparation, properties and uses of a new class of 
materials. Materials science and engineering: $\mathrm{R}$ : Reports, 2000, vol. 28, no 1-2, p. 1-63.

12. ISHIDA, Hatsuo; CAMPBELL, Sandi; BLACKWELL, John. General approach to nanocomposite preparation. Chemistry of Materials, 2000, vol. 12, no 5, p. 1260-1267.

13. SANDLER, J., et al. Carbon-nanofibre-reinforced poly (ether ether ketone) fibres. Journal of Materials Science, 2003, vol. 38, no 10, p. 2135-2141.

14. LOZANO, Karen, et al. Investigation of the electromagnetic interference shielding of titanium carbide coated nanoreinforced liquid crystalline polymer. Journal of Applied Physics, 2009, vol. 105, no 10, p. 103511.

15. FORNES, T. D.; YOON, P. J.; PAUL, D. R. Polymer matrix degradation and color formation in melt processed nylon 6/clay nanocomposites. Polymer, 2003, vol. 44, no 24, p. 7545-7556.

16. PAREDES, J. I.; MARTINEZ-ALONSO, A.; TASCÓN, J. M. D. Surface characterization of submicron vapor grown carbon fibers by scanning tunneling microscopy. Carbon, 2001, vol. 39, no 10, p. 1575-1587.

17. ENDO, M., et al. Structural characterization of carbon nanofibers obtained by hydrocarbon pyrolysis. Carbon, 2001, vol. 39, no 13, p. 2003-2010.

18. Ramesh Srinivasan, Kirk Young, Norm Ricci, Jeff Sawka, Consumer / Extrusion Team, Ticona Polymers Inc., A Business of Celanese AG

19. DI MAIO, Ernesto, et al. Isothermal crystallization in PCL/clay nanocomposites investigated with thermal and rheometric methods. Polymer, 2004, vol. 45, no 26, p. 8893-8900.

20. SEO, Min-Kang; LEE, Jae-Rock; PARK, Soo-Jin. Crystallization kinetics and interfacial behaviors of polypropylene composites reinforced with multi-walled carbon nanotubes. Materials Science and Engineering: A, 2005, vol. 404, no 1-2, p. 79-84. 